\title{
Socio-economic Impacts of Bahir Dar Tannery: Bahir Dar, Ethiopia
}

\author{
Fitsum Dechasa Kibret ${ }^{*}$, Fikirte Demissie Tulu \\ Department of Geography and Environmental Studies, Bahir Dar University, Bahir Dar, Ethiopia \\ *Corresponding Author: laryfdk@yahoo.com
}

Copyright (C) 2014 Horizon Research Publishing All rights reserved

\begin{abstract}
This study focuses on Bahir Dar Tannery, to assess its socio-economic impacts and examine the level at which the tannery implemented EIA recommended mitigation measures. To achieve the objectives of this research primary data was collected from different group. A total of 100 household heads who reside near the tannery; 100 workers and one technical manager of the tannery; and three officers of Environmental Protection Agency were consulted. As a labor based export oriented industry the tannery is beneficial for the surrounding community by creating employment opportunity and for the country at large by generating foreign currency. Despite such benefits, due to the absence of proper waste treatment and disposal system and inadequate safety equipments, the tannery is causing adverse impacts on the workers and the community. The tannery disposes its solid and liquid wastes, with little if any treatment, to the nearby Abbay (Blue Nile) river which is the main source of water for the surrounding community. Hence, the community is exposed to different health hazards like asthma and water related diseases. Their domestic animals are also adversely affected as they usually drink the river water. Although Bahir Dar tannery established before the endorsement of Ethiopia's EIA proclamation (Proclamation No 299/2000), the tannery is expected to have adjustments to make its activities environmentally friendly. Intervention programs of the tannery should, therefore, aim at implementing a proper and more efficient waste treatment and disposal system.
\end{abstract}

Keywords Socio-economic Impact, Tannery, Environmentally Friendly, Mitigation Measures, Waste Disposal

\section{Introduction}

\subsection{Background}

In the past decades urban areas of developing countries have undergone rapid changes that have transformed the urban landscape as well as the lives of millions of peoples.
Like other developing nations, Ethiopia, particularly urban centers of the country, which are the centers of industrial expansion, are experiencing socio-economic and environmental problems resulting from industrial pollution. Leather industries, both tanning and manufacturing of leather products, are among the various industries which are causing such environmental and social impacts.

Tanneries are generally pollution-intensive industrial complexes generating large volumes and high concentration of liquid and solid wastes. These wastes have historically been discharged in to the rivers, land fill waste sites and to the air with little if any purification [6]. Because tanneries use different harmful chemicals (Sodium Sulfide; Sulfuric Acid; Chrome etc) in their processing, they could have a number of adverse impacts on the ecology as well as the society. However, tanneries are not all alike. There are tanneries which use primary or secondary effluent treatment plants that could help for proper treatment and discharge of wastes. Though in most cases they are blamed for their negative impacts, tanneries have also their own positive impacts. But the extent of the positive and negative impacts requires detailed studies.

In Ethiopia attempts have been made by governmental organizations such as Environmental Protection Authority (EPA) to address impacts related to tanneries. EPA as a national environmental protection organ and other Sectoral and Regional Environmental Protection Agencies, having the responsibility of protection or regulation of the environment and natural resources, are undertaking EIA monitories or follow-up activities. This is to ensure that impacts of projects, policy and programs are adequately and appropriately considered and mitigation measures for adverse significant impacts incorporated when decisions are taken. But during literature review no prior work was found regarding how far the Amhara Regional Environmental Protection Agency is doing these follow-up activities on different projects of the region, of which Bahir Dar tannery is the one. Moreover, despite the presence of research works on issues related to tanneries $[9,10,11,15]$, these studies highly focused on the impacts of tanneries on the ecology, with less emphasis on the socio-economic impacts. Their research finding revealed that in Ethiopia solid wastes and 
effluents from tanneries are the major causes of environmental contamination.

In line with these assertions, this research argues that these gaps deserve further studies. Accordingly, this research aims to address the stated research problem using quantitative and qualitative analysis and provide a better understanding of the socio-economic impacts of Bahir Dar tannery. The tannery is a privately owned company established in 1998. It gains its inputs (hide and skin) from the surrounding community, the municipal slaughterhouse of the town and from wholesale merchants who collect hide and skin from the local people. In the earlier periods of its establishment the tannery was known for semi-processed products like pickled sheepskins and chromed goat skins. These products were exported to Italy, England, and Indonesia. Currently, however, the tannery is producing Crust and finished and semi-finished leathers like garment, glove leather, upper shoe leather, leather bags which are exported to Germany, Holland, China, Indonesia and India.

\subsection{Objectives}

The main objective of this research is to investigate the socio- economic impact of Bahir Dar Tannery.
Specifically the research intended:

To assess the socio-economic impacts of Bahir Dar tannery on the workers and surrounding community.

$\rightarrow \quad$ To examine the level at which EIA recommended mitigation measures have been implemented by Bahir Dar tannery.

- To examine the kind of support Bahir Dar tannery gains from the local government to scale up its activity.

\section{Study Area and Methodology}

\subsection{Study Area}

The study was conducted at Bahir Dar Tannery which is situated in Bahir Dar town, the capital of Amhara National Regional State of Ethiopia. The town is situated at $578 \mathrm{~km}$ northwest of Addis Ababa the capital of Ethiopia. In its absolute location it is found $11^{0} 33^{\prime} 15^{\prime \prime}$ and $11^{0} 36^{\prime} 53^{\prime \prime}$ north latitude and $37^{\circ} 21^{\prime} 11^{\prime \prime}$ and $37^{\circ} 25^{\prime} 49^{\prime \prime}$ east longitude. The town has been the capital of Amhara National Regional State since 1991. Currently the town covers a total area of $256.4 \mathrm{~km}^{2}$.

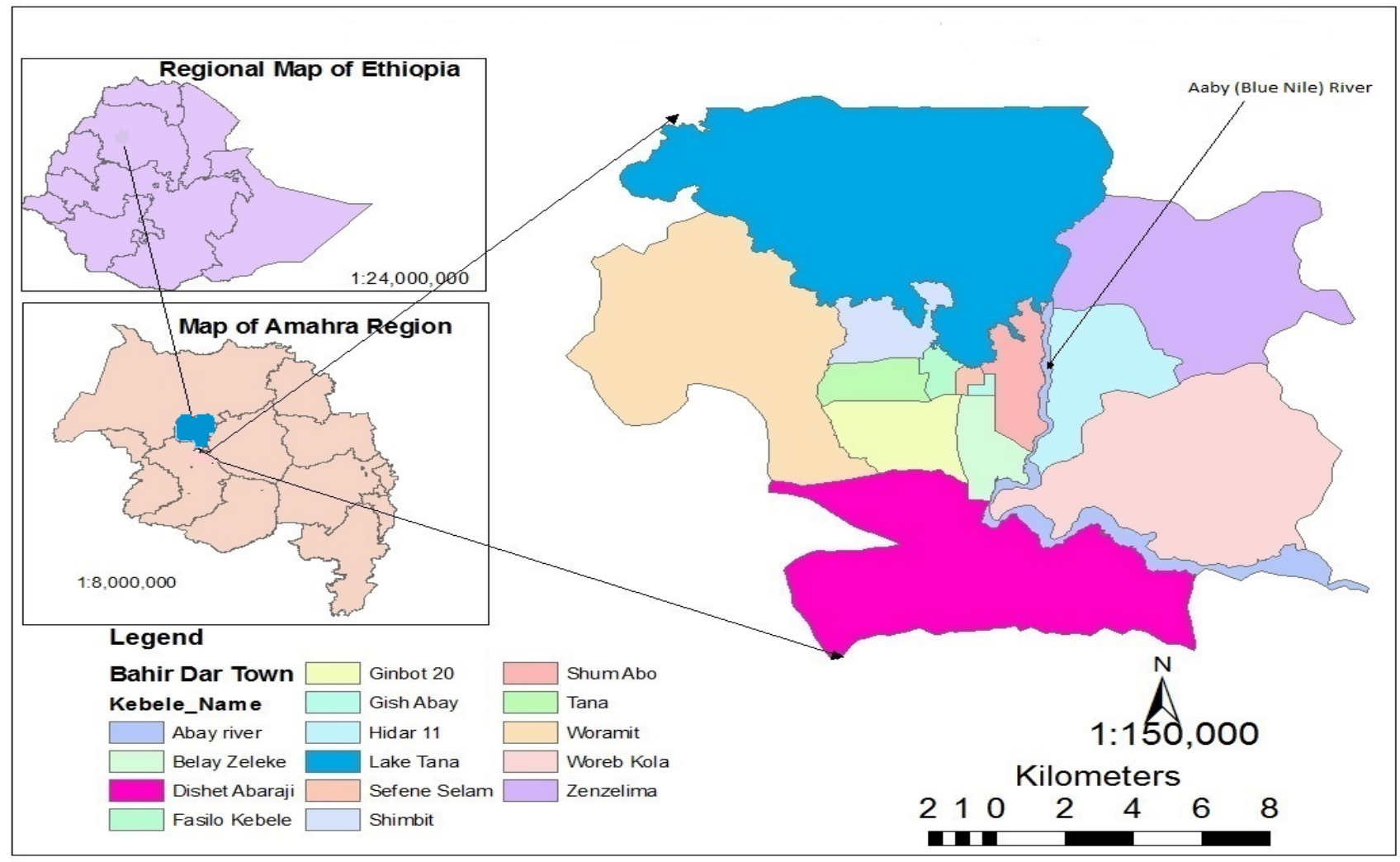

Figure 1. Location Map of Bahir Dar Town 
Bahir Dar lies on a very gentle slope with elevation ranging between $1783 \mathrm{~m}$ and 1889 meter above sea level. It occupies the head stream of the Blue Nile basin. The town is situated at the southern shore of Lake Tana a freshwater lake with weak seasonal fluctuation. At $3156 \mathrm{~km}^{2}$ in area, it is the largest lake in Ethiopia and the third largest in the Nile Basin. Of more than 40 rivers feeding the lake, Gilgel-Abay, Reb, Gumera and Magetch contribute more than $93 \%$ of the inflow. The only surface outflow is the Blue Nile, which comprises $7 \%$ of the Blue Nile flow at the Ethio-Sudanese border $[16,17]$. The town experiences a tropical climate with annual average rainfall of $1409 \mathrm{~mm}$ and average temperature of $21.3^{0}$ [3]. The area receives a maximum rainfall during summer season (June to August) and short rainfall in spring season (September and October). The rainy season accounts for nearly over $96 \%$ of the total annual rainfall [3]. The natural vegetation is mainly consisted of few remnants of different tree species, bushes, shrubs and grasses. Papyrus is dominant along the coastlines of Lake Tana and Blue Nile River. There is no more forested area in the town except some eucalyptus tree in homesteads [6].

\subsection{Methodology}

\subsubsection{Research Design}

This research is conducted to investigate the social and economic impacts of Bahir Dar Tannery on the workers and surrounding communities. Exploratory research method was selected to survey and better understand the issue under consideration. The study used a mixed approach with a central premise of the use of quantitative and qualitative approaches in combination provides a better understanding of a research problem than either approach alone [1]. Hence, the mixed approach that was used in this research employed strategies of inquiry that involved collection of qualitative and quantitative data simultaneously to best understand the research problem under investigation.

\subsubsection{Data Source}

To achieve the aims of this study, relevant data was collected from both primary and secondary sources. Primary data was gathered from the technical manager and employees of the tannery; people who reside around the tannery and officials from the regional bureau of Environmental Protection Authority and investment bureau. In an effort to augment the primary data and make this research work more valid and worthy, all relevant secondary sources pertinent to the study were reviewed. Accordingly, different written documents both published and unpublishedbooks, journals, research works etc, in relation to the issue under consideration; government policy and strategy were reviewed to supplement the study.

\subsubsection{Sampling}

Those people who are considered to be the main target of this study are workers of the tannery and peoples who reside around the tannery. As it was found to be manageable a total of 100 workers (the whole workers) and 100 households who reside around the tannery were consulted in this study.

\subsubsection{Method of Data Collection}

The general principle in research work is that, "the research strategy or strategies and the methods or techniques employed must be appropriate for the questions you want to answer" [7]. Accordingly, to attain the intended objectives of the study; questionnaires, observation, interviews were the instruments used to collect the primary data from different groups of respondents.

Accordingly, open and close ended questionnaire was employed to collect primary data from the employees about social and economic impact of Bahir Dar Tannery. Questionnaire and Semi- structured interviews were also employed to collect quantitative and qualitative data from people who are living near and around the tannery. Interviews were also conducted with the technical manager of the tannery and concerned officials of the regional Environmental Protection Agency and investment bureau. Moreover, to have a good insight about the waste disposal system of the tannery the researchers directly visited the tannery and its surrounding environment.

\subsubsection{Method of Data Analyses}

To drive specific conclusions the quantitative data which was collected through questionnaires was analyzed using simple frequency and percentage. The information gathered through tape recorder was transcribed and then translated from local language (Amharic) to English. By reading through all of the qualitative data, it was then reviewed to develop a general understanding of the data. Short memos were also prepared which best help in forming broader categories of information. Then, through narrative description the entire qualitative data was analyzed and interpreted. Lastly, to handle the research problem, the analysis and interpretation of the quantitative and qualitative data were integrated.

\section{Results and Discussions}

\subsection{Socio-economic Impacts of Bahir Dar Tannery on the Workers and Surrounding Community}

Government or private programs, policies and projects can cause potentially significant changes in many features of the socio-economic environment. In some cases the changes could be beneficial while in others they may be detrimental. Accordingly, socio-economic impact studies must systematically identify, where possible quantify and appropriately interpret the significance of these anticipated changes. The finding of this research revealed the following facts about the prevailing positive and adverse socio-economic impacts of Bahir Dar Tannery. 


\subsubsection{Benefits of Bahir Dar Tannery}

Despite considerable adverse impacts on the health of workers, local community and the ambient environment, tanning industries have significances in terms of economic gain through export market and local market opportunity from the sale of hides and skins; and generating employment opportunity. In this regard Bahir Dar tannery has some importance as it has created job opportunity for 100 individuals, 60 permanent and 40 temporary, though the income may not adequately support their living.

As the finding on the workers' income from the tannery revealed, of all the study subjects those who earn monthly income of Birr 500 or less accounted for $83 \%$, where as $17 \%$ of the total earn 501-1000 Birr per month. Despite the fact that the majorities' income from the tannery is less than 500 birr, as to the response of workers the income from Bahir Dar Tannery is the sole source of livelihood for quite a large number (91\%) of them. For these groups of respondents, although the income from the tannery was found to be inadequate to support their living, as they have no any other source of livelihood, the tannery was found to play a great role for their sustenance. What is more surprising is despite the low income they earn from the tannery, these workers have an average of 2 dependents, all of whom need their support. The main reason these respondents mentioned for not to engage in other activities to support their living is the fact that they spent 8 hours per day working in the tannery. The low educational status and limited work opportunity with in the town, Bahir Dar, are also other reasons mentioned by the respondents. On the other hand, as the income from tannery is not enough for their survival, few workers ( $9 \%$ of them) reported that in order to eke out their income from the tannery they are engaged in different part-time activities. However, their low level of education; lack of skill training and startup capital; and the very limited work opportunity draws most of them to engage in informal economic activities such as washing cloth, petty trade, baking 'Ingera', and chopping fire wood.

The researchers were interested to look at the workers' and residents' opinion about the overall benefit of the tannery for the surrounding community and the country at large. Accordingly, the study subjects (the workers and the residents) stated that in addition to the provision of job opportunity, the tannery had great benefits in creating local market opportunities. The tannery collects hides and skin from the nearby wholesalers and collectors. This account of the workers and residents is in agreement with the information provided by the technical manager of the tannery. The manager reported that, currently the tannery gains the bulk of its inputs (the hides and skin) from local wholesaler of Bure town, Gonder town and Addis Ababa city administration. Moreover, the bulk of the chemicals used for the tanning processes are also collected from Addis Ababa though sometimes imported from Europian (Germany, Spain and Italy) and Asian Countries (China and India).

As to the account of the technical manager, in order to take full advantage of the production capacity and the quality of production, and thereby to have a significant contribution to the national economy, the tannery built-up a professional and skilled team and better manufacturing facility with a better production processes. The Company's present production capacity per day has reached up to 4,000 pieces of sheep and goat skins and 50 cow hides. With regard to market destination currently the tannery exports most of its products (the processed hides and skin which can be used for production of glove, garments and shoe) to the international market, mainly to European countries -Sweden, Italy, Romania and Hungary and Asian countries -China and Japan. In so doing the tannery generate economic gain through export market.

\subsubsection{Negative Impacts of Bahir Dar Tannery}

\subsubsection{Impacts on Workers}

As tannery can be an extremely risky workplace, involving multiple hazards, the owner or employer of the tannery is responsible for the workers' safety. The owner, therefore, should be committed to communicate potential hazard information to the workers so that they can understand, get prepared and be able to avoid the hazards in advance. The employer has also the obligation to afford safety equipments to works so as to protect them from the likely adverse impacts of the tanning process. It is necessary that all workers in the tanning operation have adequate awareness and knowledge about the different kinds of chemicals and their hazardous status [2]. The most commonly needed personal protective equipments in tanneries and effluent treatment plants are protective clothing (gloves, safety shoes, aprons/ protective garment tied over the cloth), hearing protection, respirators and protective goggles/eyeglasses. If workers lack such protective devices, they could be unhealthy, less productive, miss work too often and make potentially costly mistakes [8].

In assessing the potential adverse impacts of Bahir Dar tannery the workers were asked whether or not they use protective device while working in the tannery. Accordingly, $90 \%$ of them reported as they use protective materials. To have full picture of the protective devices which are currently in place in the tannery, data was collected on the type of protective device/s used by the workers. The finding depicts that the greater proportion of the workers $(31.1 \%)$ are currently using only aprons followed by those who use apron and safety shoes (24.5\%), glove, apron and safety shoes $(21.1 \%)$, glove and apron (12.2); and the remaining $7.8 \%$ and $3.3 \%$ reported as they use only safety shoes and glove respectively.

From the finding one can conclude that even though Bahir Dar tannery is obliged to provide safety materials to workers, so that they can be protected from the likely adverse impacts of the tanning process, the safety devices are not adequately provided. Thus, the workers are facing different health hazards. For the tanning process, the 
epidermis of the hide is first removed and only the dermis transformed into leather. During this process, since the hide serves as a medium for numerous microorganisms, infection and bacterial contamination are major hazards for the workers [8]. Tetanus, anthrax, leptospirosis, epizootic aphtha/mouth ulcer, fever, and brucellosis are also the possible diseases that workers could be contracted, during the tanning process, due to infected hides [4]. For the workers of Bahir Dar tannery, although injury (for example cutting of fingers) and skin irritation are the mentioned major risks, due to the bad odor within the working environment workers frequently suffer from headache, cold and asthma.

Despite the inadequacy in the provision of safety materials to the workers, Bahir Dar tannery has also limitation in affording health insurance and full medical support in case of any work related health hazards. In fact, there are few workers who have got medical support from the tannery; a case in point is a worker who had an accident on his hand. However, as to the account of the majorities of the workers, although they frequently faced health hazards (mainly skin irritation) the tannery could not afford the cost for medical care.

\subsubsection{Impacts on the Residents}

In Ethiopia tanning industries contribute significantly towards exports and employment generation, thus have an important role in the national economy. However, as the process of tanning involves the use of large amounts of fresh water and various chemicals, tanneries' wastes are one of the highest pollutants among all the industrial wastes, especially if they are not well treated.

In a tannery, processing of hides and skins in to leather involve series of individual processes. These industrial activities in the tanning industry require extensive amount of water [11, $15]$. For $1 \mathrm{~kg}$ of hide the necessary requirement of water is 50-60 liter during tanning process. But often tanneries use three times much water than normally required for $1 \mathrm{~kg}$ of hide [12]. The discard of these wastes causes serious problems because untreated effluents of tannery have high chemical oxygen demand (COD), biological oxygen demand (BOD) and high quantities of salts like chromium, sulfide and chloride, which are highly alkaline [13].

Regarding the waste disposal system of Bahir Dar tannery the technical manager stated that currently the wastes of the tannery is being released once it has been treated using primary effluent treatment plant; and they have a plan to install secondary effluent treatment plant. However, this contradicts with the one reported by the sample respondents, officials of the regional Environmental Protection Agency; and with the one observed by the researchers. To have a full picture on the tannery's waste disposal system and related adverse impacts the sample respondents were consulted about the tannery's waste disposal system. On the basis of the majorities' (about 97\%) account, the tannery releases untreated effluent to the nearby Abay River. This has been confirmed by the researchers during site observation (Figure 2). We have observed the effluent of the tannery being discharged to the Abay River via long ditch. Though it requires detail experimental analysis to determine the extent of pollution to the river water, from a mere observation to the effluents discharged to the river one could guess the extent of pollution. Studies have also documented that direct disposal of effluents to land and water bodies has the potential to contaminate air, surface and ground water as well as soils and crops grown on the soils which will have bearing on human health $[9,14]$.

River Abay being the main source of water for domestic water consumption (for drinking, bathing, cooking, washing cloth) of the community around Bahir Dar Tannery, the majority $(61.7 \%)$ of the sample respondents claimed that the contamination of the water by the effluents of the tannery has resulted in different health hazards (such as typhoid, giardia, skin disease/irritation) to their families. These groups of respondents as opposed to the remaining $38.3 \%$ are highly vulnerable since they reside on the downstream side of the river. In this regard, different experimental research works on environmental impacts of tanneries $[9,10,11]$ found out that the extent of pollution in surrounding downstream water bodies is quite significant; and the concentration of heavy metals in different water sampling sites decrease with increasing distance from tannery. The downstream respondents further reported that the contaminated river water is not only affecting the health of their family but also their domestic animals, as they drink the river water.

Despite the adverse impacts of the effluents discharged from Bahir Dar tannery, the surrounding communities are also arguing against the bad odor emitted from the tannery. Unlike to the problem related with water contamination, the problem related to the bad odor of the tannery is commonly shared by the nearby residents of all directions. As to the report of USAID [8], strong smells can damage the quality of life around the tannery site and may reduce or destroy community support for further production or expansion. Thus, as the surrounding community is complaining about the waste discharging system of Bahir Dar tannery, the tannery is highly recommended to design and implement some more efficient waste treatment and discharge mechanisms.

In general, tannery's wastewater management inefficiency can be seen in its adverse effects on the surrounding environment and community in that the pollution threatens the ecology and human wellbeing. In all cases, it is the poorest that are the most severely affected. 


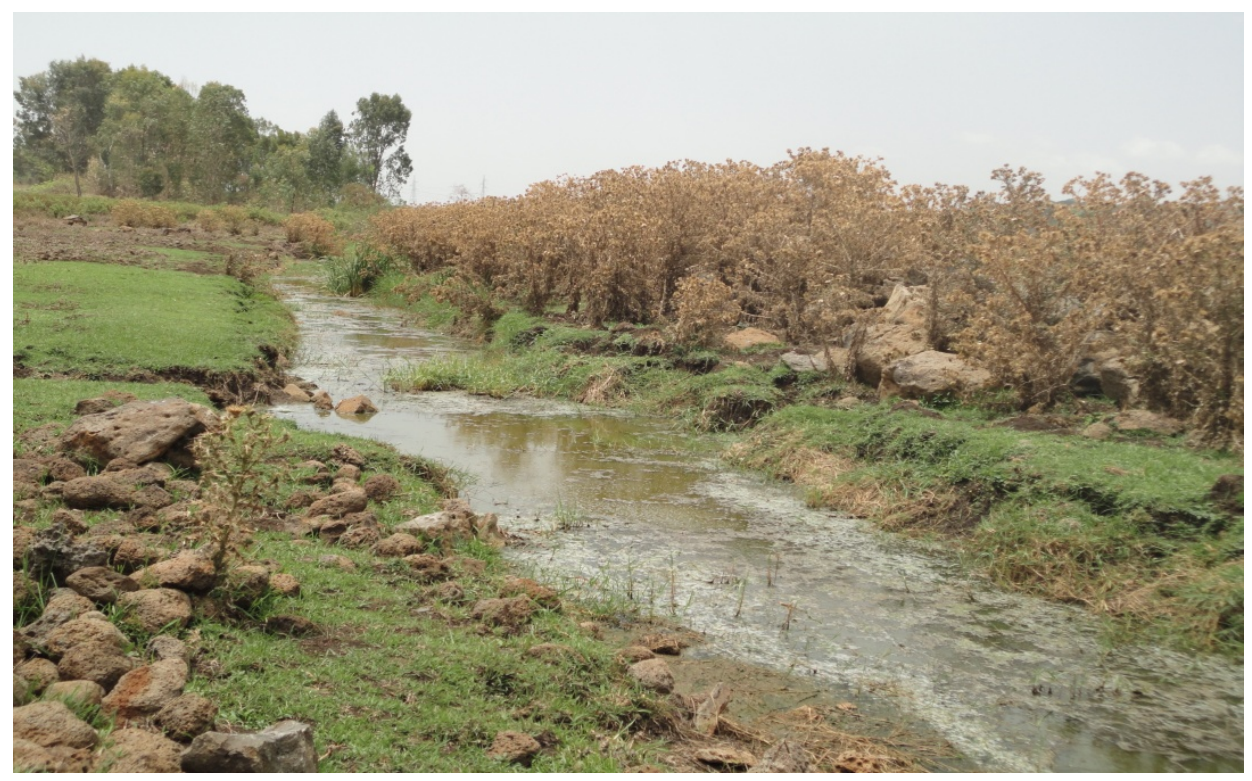

Figure 2. Disposed liquid waste of Bahir Dar Tannery (Picture by the researchers)

\subsection{Efforts of the Tannery to Implement EIA Recommended Mitigation Measures}

Because of the tremendous volume of waster and chemicals used, waste generation and the disposal of waste forms part of everyday lives which is more for industries especially tanneries (http://ietd.inflibnet.ac.in/bitsterem/10603/1616/10/10_chap ter2.pdf). Pollution remediation of these tannery wastes is of great need since they damage the normal functioning of the ecosystem. To reduce the toxicity of soil, water, air and the environment as a whole caused due to the discharge of heavy metals and contaminants from tanneries, various treatment procedures should be widely followed. The methods should aim at reducing the toxicity of the metals before letting into the land or rivers.

In Ethiopia past experience has shown that programs and projects undertaken in different sectors of the country have caused damage to the environment and to public health. This is because traditional project preparations and decisions were mainly based on short term economic and technical feasibilities and neglected the environmental, social as well as the long term economic dimensions.

Concern for environmental degradation in Ethiopia has been growing in recent years. The most important step in setting up the legal framework for the environment in Ethiopia has been the establishment of the Environmental Protection Authority by proclamation No. 9/1995. According to this proclamation the Environmental Protection Authority has amongst its 'powers and duties' to:

$\downarrow$ Prepare environmental protection policy and laws and, upon approval, follow up their implementation.

$\downarrow$ Prepare directives and systems necessary for the evaluation of the impacts of social and economic development projects on the environment; follow up and supervise their implementation.

The Environmental Protection Agency of Amhara National Regional State has the responsibility to undertake environmental monitoring and auditing of the regional developmental projects and programs, of which Bahir Dar tannery is the one. Accordingly, a committee from the regional Environmental Protection Agency has conducted environmental monitoring and audits to know the level at which the tannery is implementing the EIA recommended mitigation measures. In the year 2010/11 the agency undertook observation/audit regarding the tannery's waste disposal mechanisms. In so doing, the auditing group has identified a number of weaknesses.

As a strong side of Bahir Dar tannery, the auditing group documented the upgrading of the tannery's production process from the processing of raw hides and skins to exportable semi-finished and finished leather products. However, no improvements have been observed about the waste disposal mechanisms of the tannery. In its examination the group has identified the following major weaknesses:-

- The tannery's solid waste collection, treatment and disposal mechanism was found to be very poor;

$\rightarrow$ The effluents from washing, submerging, tanning and painting rooms pass through a non-functional waste refining ponds and then discharged to the soils and Abay river;

$\rightarrow$ The volume and amount of tannery's effluent was not known;

$\checkmark$ Lack of laboratory room and inadequate safety equipments;

Once observing these weaknesses the auditing group also suggested the following corrective measures to be 
considered by the tannery:

$\rightarrow$ Designing appropriate and efficient mechanisms for solid waste disposal;

- Using the appropriate effluent treatment and attenuation technology;

$\rightarrow$ Accomplishing laboratory test for the content of the effluent prior to its disposal and

- Install laboratory room and equipments.

In general, Bahir Dar Tannery, processing raw hides and skins to that of finished and semi-finished leather products, contribute a lot to the economy of the country. However, unless appropriate environmental monitoring and protection activities are carried out, the development efforts of this project could damage the environment and make development unsustainable. Although the tannery was established before the EIA proclamation (Proc. No. 299/2002), it is expected to have adjustments to make its activities environmentally friendly. Furthermore, the research found out that Bahir Dar tannery lagged behind in implementing the EIA recommended mitigation measures. The account from the officials of the regional Environmental Protection Agency depicted that, although they repeatedly suggested the tannery to make its activity environmentally friendly, by improving its waste management and disposal mechanism, the tannery failed to do so.

\subsection{Government Support to Scale up Bahir Dar Tannery}

Ethiopia is the first ranked nation in Africa and tenth in the world in the number of cattle, sheep and goats. The country is well known in the export of semi-processed and processed hides and skins for long period of time. In the country the tanning industry is among the largest external income earners. Thus, in the past 20 years with significant government support the Ethiopian tanning industry has got momentum and expanded remarkably throughout the nation [9]. At this time the country is encouraging many investors to participate in processing and production of finished and semi- finished leather products.

Bahir Dar tannery is one of the five tanneries that are operating in Amhara National Regional State. The tannery has planned to scale up the quality and quantity of its production and establish leather factory which could contribute a lot in job creation and earning additional foreign currency. This could be realized with the support from the government and the local community. In this regard, Bahir Dar tannery like any of the currently operating tanneries in Ethiopia has several market drivers that can promote its production capacity, some in fact backed by the policies of the government. At national level, the existence of policy support that limits export of raw skin; the existence of policy support for export of semi-finished and finished leather products; availability of local market for finished leather for further processing into shoes and other leather articles are some of the many market drivers that could encourage Bahir Dar and other tanneries of the nation to scale up their production.

The data generated from the interview with the technical manager of Bahir Dar tannery, however, revealed that the regional/local government is not assisting the tannery. To assure this the officials of the regional Environmental Protection Agency were asked about the support their office is providing for Bahir Dar Tannery. The officials reported that their office is doing all its best to support the tannery by providing professional/technical advices on how to make its activities environmentally friendly, socially acceptable and economically feasible. Thus, knowing that efficient management and treatment of tannery's waste contribute largely in reducing the negative environmental impacts and gaining communities' support for further expansion, it is the responsibility of the tannery to fulfill the required waste treatment plant.

\section{Conclusions and Recommendations}

\subsection{Conclusion}

Tanneries have undeniable advantage for the country like Ethiopia, where there is cheap human labor force, sufficient water and abundant raw hides and skin. The industry has become one of the sectors significantly supporting economic development of the nation by generating foreign currency and employment opportunity for the citizens and the nation. However, the environment and development integration in the industry is of great importance to sustain the economic benefit from it. This being also true for Bahir Dar tannery, however the activity of the tannery was not found to be environmentally friendly. Due to inadequate safety devices and the improper waste disposal mechanisms of the tannery, most workers and people who are living around the tannery are facing challenges. The workers are facing different potential health hazards, due to lack of safety/protective devices, while working in the tannery. The residents near the tannery are also suffering from different health hazards due to the untreated waste water disposed from the tannery to the nearby river.

There could be a number of challenges in managing tannery's wastes. However, a gap in integrating the individual process with the waste management activities could eventually reduce productivity, lowers cost-efficiency; adversely affect the community and the environment thereby undermine sustainable development.

\subsection{Recommendations}

The following are major recommendations that could possibly be considered for the short-run or the long-run benefits of the tannery, the environment, the workers, the community and the nation at large.

The tannery's intervention programs should first aim at implementing a proper/standardized waste treatment and disposal system. 
Efforts have to be made by the tannery to provide the most commonly needed personal protective equipments to all workers of the tannery and give support and medical treatment for those workers who are affected by different skin diseases.

- The tannery should ventilate the production sites well and control sludge to decrease odors.

$\checkmark$ The officials of the regional Environmental Protection Agency should further continue to provide professional advice to the tannery on what to do in order to make its activities environmentally friendly.

$\checkmark$ Finally, the importance of further detailed experimental research that explore the ecological impact of the tannery is highly recommended.

\section{Acknowledgement}

We are grateful to Bahir Dar University for its financial support. The enumerators and respondents deserve our warmest appreciation for their cooperation during data collection. We are also gratefully for the manager and workers of Bahir Dar tannery for their kind assistance and cooperativeness. We owe our sincere gratitude to all of the authors of the materials that we have reviewed in this research as well as individuals and offices who provided us the necessary data and information.

\section{REFERENCES}

[1] J.W. Creswell, V.L. Plano Clark. Designing and Conducting Mixed Methods Research. Sage Publication University of Nebraska Lincoln. New Delhi, India, 2007.

[2] EFDRE, EPA. Environmental Impact Assessment Guideline for Tanneries. Addis Ababa Ethiopia, 2005

[3] EMA. Ethiopian Meteorology Agency: Summary of Statistical Report. Addis Ababa, Ethiopia, 2009

[1] ISBE. Indoor and Built Environment: Biological Hazards in Tannery Workers, 2007. Online Available: http://ibe.sagepub.com/content/16/4/349 Accessed on 28 October, 2011.
[4] K.B. Lawrence, R.R. Ernest, L.Z. William. Processing Chrome Tannery Effluent to Meet Best Available Treatment standards, 1999.

[5] Leykun Getaneh. Assessment of Land use and Morphological changes of Bahir Dar using GIS and Remote sensing. Bahir Dar University. M.A. Thesis, Department of Geography and Environmental Studies. Bahir Dar, Ethiopia, 2008.

[6] C. Robson. Real World Research: A Resource for Social Scientists and Practitioner - Researchers. (2nd ed.). Black Well, Oxfam, USA, 2002.

[7] USAID Environmental Guidelines for Small-Scale Activities in Africa (EGSSAA), 2009.

[8] Abraha Gebrekidan, Gebrekidan Gebresellasie and Afework Mulugeta. Environmental Impacts of Sheba Tannery (Ethiopia) Effluents on The Surrounding Water Bodies. Chemical Society of Ethiopia. Ethiopia, 2009.

[9] Aklilu Asfaw. Heavy metal concentration in tannery effluents associated surface water and soil at Ejersa area of East Shoa, Ethiopia. Herald Journal of Geography and Regional Planning Vol.3 (3): 124-130, 2014.

[10] Aklilu Asfaw, Mengistu Sime, Fisseha Itanna. Determining the Effect of Tannery Effluent on Seeds Germination of Some Vegetables in Ejersa Area of East Shoa, Ethiopia. International Journal of Scientific and Research Publications, Volume 2, Issue 12, 2012.

[11] P. Indira, T. Ravi. Germination Changes of Vegetables of Vigna Mungo L. under Tannery Effluent Stress, 2006.

[12] Z. Bajza, I.V. Vrcek. Water Quality Analysis of Mixtures Obtained from Tannery Waste Effluent, Ecological and Environmental Safety Vol.50, p.15-18. 2001.

[13] M.P. Khurana, S. Pritpal. Waste Water Use in Crop Production Resources and Environment Vol. 2(4), p.2163-2618, 2012.

[14] R.A.Daryapurkar, N. Deshpande, S.N. Kaul. Recovery of useful by products from Tannery wastes. Ind.j.env.prot.9: 890 $-898,2009$.

[15] M. Shahin. Hydrology of the Nile basin, International Institute for Hydraulic and Environmental Engineering. Elsevier, The Netherlands, 1988.

[16] D. Conway. The Climate and Hydrology of the Upper Blue Nile River. The Geographical Journal 166, 49-62, 2000 